\title{
Ulisses de Joyce en català: les traduccions de Joan Francesc Vidal Jové, Joaquim Mallafrè i Carles Llorach-Freixes
}

\author{
Teresa Iribarren \\ Universitat Oberta de Catalunya. Estudis d'Arts i Humanitats \\ Av. Tibidabo, 39-43 \\ 08035 Barcelona \\ tiribarren@uoc.edu \\ ORCID: 0000-0002-5052-7770
}

\section{Resum}

Ulisses, de James Joyce, ha estat girat al català per Joan Francesc Vidal Jové (la seva traducció, enllestida el 1966, encara roman inèdita), per Joaquim Mallafrè (1981) i per Carles LlorachFreixes (2018). A fi d'indicar les principals característiques de cada versió, exposem les condicions que en van determinar la tasca, apuntem el sentit dels paratextos en Vidal i en la retraducció de Llorach i, finalment, fem una anàlisi comparativa d'un passatge especialment compromès: l'escarni religiós de l'inici de la novellla.

Paraules clau: traducció al català; retraducció; Ulisses; James Joyce

Abstract. Joyce's Ulysses into Catalan: Joan Francesc Vidal Jové, Joaquim Mallafrè and Carles Llorach translations

Ulysses, by James Joyce, has been translated into Catalan by Joan Francesc Vidal Jové (his translation, completed in 1966, still remains unpublished), by Joaquim Mallafrè (1981) and by Carles Llorach-Freixes (2018). In order to point out the main characteristics of each version, we set out the conditions that determined their task, we point out the meaning of the paratexts in Vidal and in Llorach's retranslation and, finally, we make a comparative analysis of a passage especially awkward: the religious mockery of the beginning of the novel.

Keywords: translation into Catalan; retranslation; Ulysses; James Joyce

\section{Sumari}

1. Introducció 4. Un tast de les traduccions

2. Els traductors i les condicions

5. Conclusions

de traducció

Referències bibliogràfiques

3. Els paratextos 


\section{Introducció}

Ulysses, de James Joyce (Dublín, 1882 - Zuric, 1941), ha estat una de les obres més influents, controvertides i estudiades de la literatura contemporània. Segons que sosté el professor i traductor Francisco García Tortosa, és «la novela por antonomasia del siglo XX» (2003 [1999]: LXXIII); el professor i traductor Joaquim Mallafrè, al seu torn, considera que es tracta de «l'última gran obra de la Galàxia Gutemberg» (Guzmán 2018). ${ }^{1}$ Publicada el 1922 a París per l'editora Sylvia Beach, ha viscut una complexa història editorial, amb múltiples i sempre controvertides edicions —especialment la sinòptica i crítica que va establir Hans Gabler el 1984. Els darrers decennis, a més, la història de l'Ulisses s'ha nodrit d'embrollades anècdotes protagonitzades pel geniüt marmessor del novellista, Stephen Joyce —el darrer hereu de la família, que va morir el 23 de gener de 2020-, el qual es va dedicar a denunciar, amenaçar i a imposar solucions capricioses a editors, traductors - no els permetia, per exemple, que el seu nom constés a la coberta del llibre,$-{ }^{2}$ programadors teatrals, etc., d'arreu del món per defensar — sostenia ell— l'obra de l'avi.

Un dels elements que, sens dubte, ha contribuït a forjar l'aura mítica d'aquesta cimera del Modernism és l'extrema dificultat — però també el plaer- de traduir-la (Walsh 2016), atesa la naturalesa experimental de la voluminosa novel-la:

Son particularmente difíciles para el traductor de Ulysses los innovadores recursos narrativos y parodias discursivas; la especificidad estilística de cada episodio; las alusiones histórico-políticas y culturales; los juegos de palabras, leitmotivs y connotaciones; las múltiples variedades lingüísticas; y, finalmente, los neologismos y efectos poéticos de gran sonoridad. El traductor debe enfrentarse, en definitiva, a una prosa poética y polivalente en la que código y mensaje tienen la misma relevancia. (Conde-Parrilla 2012: 2)

La interdependència entre canonització i retraducció que postula Venuti (2004) és paradigmàtica en el cas de la novellla joyceana: gairebé cent anys després de la seva polèmica primera edició, i en domini públic des del 2012 a la majoria de països — amb la clamorosa excepció de l'Estat espanyol—, disposa de dues traduccions al francès, ${ }^{3}$ cinc al portuguès ${ }^{4}$ i cinc a l'italià. ${ }^{5}$ En l'àmbit hispà-

1. Modern Library la situa en primer lloc en la llista de les 100 millors novelles en llengua anglesa (<http://www.modernlibrary.com/top-100/100-best-novels/>).

2. Així, si bé en la primera edició de la traducció de Joaquim Mallafrè, publicada a Leteradura (1981), a la coberta blanca hi consta «Traducció de J. Mallafrè», tant en l'edició d'Edhasa (1990) com en la de Proa (2004) no hi apareix. En l'Ulisses de l'Editorial Funambulista (2018) tampoc no consta el nom del traductor, Llorach-Freixes, a la coberta.

3. La pionera, d'Auguste Morel (1929), feta amb l'ajut de Stuart Gilbert, revisada per Valery Larbaud i Joyce mateix, i editada per Adrienne Monnier a La maison des Amis des Livres (Corbí 2002), i una de collectiva, dirigida per Jacques Aubert i editada per a Gallimard (2004, revisada el 2013) (Peeters 2016: 643-645).

4. Tres han estat publicades al Brasil, signades per Antônio Houaiss (1966), Bernardina da Silva Pinheiro (2005), Caetano Galindo (2021); i dues a Portugal, de João Palma-Ferreira (1989) i Jorge Vaz de Carvalho (2013).

5. De Giulio De Angelis (1960), Bona Flecchia (1995), Enrico Terrinoni i Carlo Bigazzi (2012), Gianni Celati (2013) i Mario Biondi (2020). 
nic, nou traductors s'han embrancat en el complex repte de girar-la: José Sala Subirats (1945), José María Valverde (1976), Francisco García Tortosa i María Luisa Venegas Lagüéns (1999), Marcelo Zabaloy (2015) i Rolando Costa Picazo (2017) 1'han traduïda al castellà; ${ }^{6}$ Joan Francesc Vidal Jové, Joaquim Mallafrè (1981) i Carles Llorach-Freixes (2018) al català.

Si Isabelle Vanderschelden (2000: 1555, citada per Jané-Lligé 2017: 69) assenyala com a raons més comunes per a la retraducció la naturalesa insatisfactòria de la traducció preexistent, la publicació d'una nova edició de l'original (com la de Gabler), l'envelliment lingüístic i cultural de la versió prèvia, l'assignació d'una nova funció (una adaptació escolar d'un clàssic, per exemple) i la nova proposta interpretativa del retraductor, en el cas del clàssic de Joyce — diriaconvé tenir-ne en compte dues més. La primera, que els traductors expliciten en l'argumentació a l'hora de presentar la retraducció: a causa del llegendari repte hermenèutic, volen acompanyar el text literari amb paratextos aclaridors de naturalesa acadèmica a fi d'equipar el lector per entendre l'obra millor — com en el llibre de Càtedra, en traducció de García Tortosa i Venegas Lagüéns (1999). I la segona, implícita, que vol matisar la percepció comuna de la contraposició entre l'autor, que s'identifica per l'originalitat i per plasmar una expressió pròpia en un text únic, i el traductor, que elabora una obra imitativa que ni és única ni articula una expressió pròpia (Venuti 1995: 25): atesa la dificultat que implica fer arribar la novellla joyceana a uns lectors d'una altra llengua, assumir-ne la temerària empresa pot comportar la celebritat i, tal vegada, aconseguir que la retraducció i el nom i la imatge de qui la signa, de bracet de Joyce, s'instal-lin en la història de la literatura. ${ }^{7}$

Quant a les lletres catalanes, la del manresà Vidal Jové, que va ser la primera traducció completa a l'Estat espanyol, encara roman inèdita tot i haver obtingut el vistiplau de la censura en la sol-licitud presentada a l'administració el 7 de març de 1967, i que se'n conservin dos exemplars mecanoscrits (Lázaro 2007; Lázaro i Iribarren 2010; Iribarren 2011; Iribarren 2012b). Per tant, per bé que des del 2007 el professor Alberto Lázaro ja va donar a conèixer «el misterio del primer Ulises catalán», la traducció de Mallafrè continua sent considerada la pionera en català. ${ }^{8}$

6. La primera traducció al castellà, signada per José Salas Subirat, veié la llum a Buenos Aires el 1945, al segell de Santiago Rueda. La segona, del professor José María Valverde, va publicar-la la barcelonina Lumen el 1976; és a dir, deu anys després de quan va fer-la Vidal. La traducció del catedràtic va ser reconeguda amb el Premio Nacional de Traducción del 1978. Fins al 1999 no apareix una nova traducció, signada pel catedràtic de la Universidad de Sevilla Francisco García Tortosa y per $\mathrm{M}^{\mathrm{a}}$ Luisa Venegas Lagüéns, publicada per la madrilenya Cátedra. El 2015 l'editorial El Cuenco de Plata, també de Buenos Aires, publica una nova versió a càrrec de Marcelo Zabaloy. També a Buenos Aires, el 2017, veu la llum una nova versió argentina, signada pel professor de la Universidad de Buenos Aires i de la Universidad de Belgrano, Rolando Costa Picazo: es tracta d'una edició crítica amb comentaris i notes, publicada — com la segona edició de Mallafrè_ per Edhasa. Segons que sosté Juan Jesús Zaro, les retraduccions espanyoles de l'Ulisses són un exemple de retraducció passiva (2007: 22).

7. Si Morel i Salas Subirat han passat a la història de la literatura és, justament, per haver traduït aquest clàssic modern.

8. L'article de celebració del Bloomsday del 2020 a Núvol, que se suma a la divulgació de la figura de Vidal Jové (Aldea 2020), és indicatiu que la traducció del manresà comença a ser coneguda. 
Per a la institució literària catalana, la traducció del reusenc, publicada per Leteradura gràcies a la contribució d'un centenar de mecenes com ara Maria Aurèlia Capmany, Pasqual Maragall, Albert Ràfols-Casamada - Mallafrè indica que es va aconseguir un milió de pessetes per a l'edició (Guzmán 2018)—, va resultar doblement significativa. D'una banda, la novella, que va ser l'estrella del Sant Jordi de 1981 — amb gran èxit de vendes i crítica, i un estimable ressò als mitjans-, es va veure com una fita amb valor simbòlic per a una literatura que havia patit la repressió franquista durant decennis i que encara sentia els estralls de la censura: el català ja havia anostrat el gran clàssic modern (Iribarren 2004a). Així, s'homologava a les literatures veïnes. D'altra banda, l'estudi de Mallafrè Llengua de tribu i llengua de polis (1991), en bona part deutor del treball i les reflexions derivades de la traducció de l'Ulisses, és considerada l'obra fundacional dels estudis traductològics catalans. En aquest alliçonador assaig, Mallafrè no fa cap referència a la traducció feta per Vidal Jové vint-i-cinc anys abans, perquè fins molts anys més tard no va tenir-ne cap notícia. ${ }^{9}$ L'obra de Mallafrè — que ell mateix va revisar tenint en compte el text corregit de Gabler, i que va ser publicada de nou el 1990 en l'emblemàtica editorial Proa com a «Clàssic Modern»—, lògicament, no pot considerar-se una retraducció: el reusenc mai no va disposar d'una traducció preexistent.

Aquestes consideracions tot just formulades convé tenir-les en compte a l'hora de llegir la darrera versió que ha vist la llum en català, la signada per Carles Llorach-Freixes, que va ser finalista al IV Premi PEN de Traducció al català. La seva és, doncs, l'única retraducció de l'Ulisses de Joyce en català. Naturalment, Llorach ha hagut de justificar la seva retraducció davant la canònica versió del professor Mallafrè, guardonada amb el Premi de la Generalitat i el Premi Serra d'Or i aplaudida pel món acadèmic, entre d'altres motius, per la creativitat lèxica (Pujol 2012, 2013). Quan ho fa, a diferència de García Tortosa quan justifica la seva retraducció en relació amb les dues preexistents en castellà, ${ }^{10}$ posa en primer terme el reconeixement a l'elogiada tasca de Mallafrè. Contràriament al que sol ser habitual, no «souligne sa vieillesse, son excès de zèle idiomatique, ses carences de fidélité, face auxquels la retraduction est présentée, souvent pour des raisons commerciales qui ne disent pas nécessairement grand-chose sur sa forme, comme étant novatrice, fraîche, respectueuse et fidèle mais non pas servile» (Peeters 2016: 637-638), sinó tot al contrari. Al portal de l'editorial hi figura a manera de presentació:

9. El professor Mallafrè m'ho va assegurar en una conversa personal durant els XXIV Encuentros de la Asociación Española James Joyce celebrat a Barcelona el 2013 (Institut d'Estudis Catalans, 24-25 d'abril).

10. Durant els anys que el professor García Tortosa va treballar en la seva versió, va justificar la necessitat d'una retraducció al castellà de la novel-la: tant Sala Subirats com el professor Valverde - blasmat per Saer (2012) per no fer cap referència a la versió de l'argentí i, per tant, per no presentar la seva obra com a retraducció- havien comès errors de comprensió de l'anglès, s'havien permès llicències innecessàries, i sobretot, havien estat desencertats en el trasllat d'harmònics i repeticions (García Tortosa 1994). 
N'existeix ja una excelllent traducció al català (1980) a càrrec de Joaquim Mallafrè. Però és un text net, sense informació addicional, i això comporta problemes de recepció. Pensem que una mica d'ajuda és essencial per fer de l'Ulisses un llibre a l'abast d'un gran públic. Per això acompanyem el text d'una breu introducció per a cada episodi $i$ gran abundància de notes a peu de pàgina. ${ }^{11}$

Per bé que des del 18 de febrer de 2013, a l'entrada d'Ulisses de la Viquipèdia s'informa sobre l'existència de la traducció de Vidal Jové, ${ }^{12}$ i que amb una senzilla cerca a internet fàcilment es pot accedir a articles i estudis acadèmics que també l'aborden, ${ }^{13}$ Llorach-Freixes ha preferit no fer-hi cap esment, tot i que en la tertúlia radiofònica dedicada a l'Ulisses que va fer Catalunya Ràdio per celebrar el Bloomsday 2018, radiada just quan la retraducció publicada per l'Editorial Funambulista acabava d'arribar a les llibreries, explica que n'estava al corrent. Hem d'entendre, doncs, que no va consultar el mecanoscrit salvaguardat a l'Archivo General de la Administración d'Alcalá de Henares i que només va collacionar el text joyceà amb la versió de Mallafrè.

El propòsit d'aquest estudi és caracteritzar, a grans trets, la naturalesa de les tres traduccions catalanes a partir dels paratextos de la primera i la tercera i d'un petit tast de totes tres. El passatge escollit és especialment compromès: es tracta de l'escarni a la missa catòlica amb què la novellla s'inicia. Considero que per poder sospesar bé les propostes textuals, que com veurem, es basen en textos de partida diferents, cal apuntar breument les condicions de traducció que van tenir Vidal Jové, Mallafrè i Llorach-Freixes, que són radicalment distintes i que, per tant, per força van condicionar la idiosincràsia del text; per això les esbossaré a manera de preàmbul. Penso que conèixer aquests tres casos contribueix a conèixer millor la història de la pràctica traductològica i, al capdavall, l'espai literari català. En darrera instància, assenyalaré l'aportació que ha significat la retraducció de Llorach-Freixes.

\section{Els traductors i les condicions de traducció}

El Diccionari de la traducció catalana (Bacardí i Godayol 2011) informa que l'autodidacte Joan Francesc Vidal Jové (Manresa, 1899 - Newcastle, 1974) es dedicà, durant els anys cinquanta i seixanta, a traduir al castellà obres catalanes - la més rellevant, Tirant lo Blanc (1969), de Joanot Martorell_ i franceses, i que només en una sola ocasió va girar una obra de l'anglès: l'Ulisses. Installlat a Madrid des del 1941, va traduir l'obra de Joyce en unes condicions del tot adverses. D’entrada, no sabia anglès. En segon lloc, era conscient que el seu text, amb

11. <http://www.funambulista.net/2018/ulisses/>.

12. A l'entrada s'hi enllaça l'article en què es detalla el rocambolesc relat de l'encàrrec, execució i presentació a censura de l'obra, així com el periple del segon mecanoscrit (Iribarren 2012b).

13. És el cas de «La fascinació catalana per James Joyce» al digital Núvol (Iribarren 2013), «La primera traducción al catalán del Ulises de Joyce quedó inédita» a La Vanguardia (Massot 2015) i l'entrada de Joan Francesc Vidal Jové al Diccionari de la traducció catalana (Bacardí i Godayol 2011), publicada en línia a Visat (Iribarren s.d.). 
multitud d'irreverències i procacitats, seria escrutat pels ulls inquisitius dels censors franquistes, que tenien potestat per amputar-lo i fer-hi objeccions de tipus polític, religiós, moral i d'estil. ${ }^{14}$ Per acabar-ho d'adobar, mentre ell estava immers en el projecte, es va promulgar la nova Llei de Premsa, l'anomenada Llei Fraga, que va entrar en vigor el 18 de març de 1966. I, en tercer lloc, Vidal vivia allunyat del context cultural, intel-lectual i llibresc català —és a dir, possiblement sense traduccions al català d'autors clàssics, del cristianisme i de la tradició anglesa, sobretot Shakespeare, citats textualment a la novellla.

El gener de 1966, Antonio Herrero Romero, director del segell barceloní A. H. R., va fer-li un encàrrec rocambolesc (per telèfon i correu postal): li donava només quatre mesos de coll per traduir el text joyceà, que havia de ser el segon lliurament de la nova collecció catalana que Herrero havia posat en marxa, «La Renaixença», inaugurada per la versió catalana del Decameron (1964) de Boccaccio, i havia d'anar encapçalada per un pròleg de Camilo José Cela (Lázaro 2007). Vidal, és clar, de seguida va adonar-se que Herrero desconeixia quina mena de llibre era Ulisses. No podia comptar, doncs, amb cap mena d'ajut de l'editor, que més aviat va posar-li les coses difícils (Iribarren 2012b) ${ }^{15}$ Per la correspondència conservada entre Vidal, Herrero i altres corresponsals amb qui abordà la qüestió de la traducció (Lázaro i Iribarren 2009), com Tomàs Garcés, sembla que el manresà desconeixia l'existència de la traducció de Salas Subirat i, per descomptat, de l'única guia de referència que aleshores ja havia vist la llum, James Joyce's 'Ulisses', de Stuart Gilbert (1958). A més, no va ser fins just l'any següent que va aparèixer la primera traducció completa d'una obra de Joyce al català: Retrat de l'artista adolescent (1967), en traducció de Maria Teresa Vernet. Per tant, no disposava de cap obra joyceana en català com a referent. ${ }^{16}$

Amb tota aquesta colla de despropòsits, com va sortir-se'n? Segons que explica la seva filla, Assumpció Cheney, va fer una traducció indirecta. Vidal, gran coneixedor del francès, ${ }^{17}$ va emprar la prestigiosa traducció d'Auguste Morel (1929) —-supervisada pel mateix Joyce —, que collacionava amb l'original. A més, tenia l'ajut del gendre, l'hispanista anglès G. J. G. Cheyne, professor de la Universitat de Newcastle, especialista en Joaquín Costa, i d'Assumpció mateixa, que van indicar algunes correccions menors en bolígraf. ${ }^{18}$ Quant als ter-

14. Tot i això, Vidal no es va autocensurar, com ja he demostrat en un altre lloc (Iribarren 2011).

15. Una evidència més que Herrero tenia un coneixement superficial de la novel-la és que havia d'aparèixer en la nova colllecció en català que acabava d'encetar, «La Renaixença», que només tenia una sola traducció, el Decameró de Boccaccio.

16. Vidal devia desconèixer les traduccions de Joyce d'abans de la guerra (Iribarren 2004a, 2004b), que, a més, tampoc no tenia a l'abast a Madrid.

17. En exiliar-se l'octubre de 1936, Vidal i la seva família van fugir a França, on van viure fins al 1941. Vidal va traduir al castellà obres de Balzac, Rabelais, Rimbaud, el marquès de Sade i Zola, entre d'altres. Una altra traducció, feta el 1966 mateix i que també havia quedat inèdita, L'illa dels pingüins, d'Anatole France, es publicà en accés obert —en versió bilingüe i accessible en multiformat - el 2016 al portal de la UOC InLector (<https://inlector.wordpress.com/2016/05/04/ lile-des-pingouins/>) (Iribarren, Oliver i Peiró 2017).

18. A l'inici del mecanoscrit hi consta: «Versió catalana de J. F. Vidal Jové revisada pel professor G. J. G. Cheyne de la Universitat de Newcastle upon Tyne i la Doctora A. F. Cheyne. Madrid 1966». 
minis, després de negociar-los, Vidal va aconseguir disposar, finalment, de set mesos. Amb la tecnologia de l'època, això és, la màquina d'escriure i el paper de calc, va aplegar en quatre volums enquadernats en vermell les 1.082 de pàgines del seu mecanoscrit, que són els que Herrero va lliurar a l'administració de censura. No es pot perdre de vista que Vidal, naturalment, comptava que la traducció passaria per les mans d'un corrector, que faria les esmenes convenients. El text que ens ha llegat, doncs, presenta els problemes habituals d'un text mecanografiat amb presses, sense cap mena de tractament editorial.

Les condicions de treball i la trajectòria professional de Joaquim Mallafrè (Reus, 1941) van ser ben diferents. Com és ben sabut, el reusenc es va professionalitzar com a acadèmic: va ser professor de la Universitat Rovira i Virgili fins a la seva jubilació, l'any 2006. Gran coneixedor de la llengua anglesa (el curs 1967-1968 va ser lector a Shropshire), abans d'enfrontar-se al magne repte havia dut a terme una primera traducció de l'anglès el 1974, de John Osborne, i a més, ja havia adquirit un bagatge joyceà: havia llegit l'Ulisses feia uns anys (1991: 70), en castellà, perquè aleshores encara no sabia anglès — si bé, com ha confessat públicament, no el va acabar (Guzmán 2018). Mallafrè ha explicat també que va començar a traduir-lo purament com a exercici, quan era professor a la Universitat Rovira i Virgili, i que en mostrar el primer capítol a Jaume Vidal Alcover i a Maria Aurèlia Capmany, van esperonar-lo a dur a cap la totalitat de la traducció. Mallafrè va treballar amb tres versions, una de mecanografiada amb una Hispano-Olivetti i una altra de manuscrita (Guzmán 2018).

A propòsit de la publicació de la traducció a Edhasa, Joan Josep Isern explicava (1900):

Iniciada pel seu compte l'any 1972 va ocupar-li el mateix temps — set anys— que Joyce va esmerçar a escriure la novellla. Això dóna una idea de l'escrupolositat del treball del professor reusenc. La versió de Mallafré, una autèntica recreació, recull expressions de l'argot popular del Baix Camp, cançons populars, refranys i, quan ha de reproduir referències textuals de Shakespeare o de l'Odissea, utilitza les traduccions originals que Sagarra, Magí Morera o Carles Riba varen fer en el seu moment. ${ }^{19}$

Quant a la polèmica edició de Gabler, Isern afegia:

En aquest sentit el mateix Mallafré escrivia el novembre passat a la revista Cultu$r a:$ «... no us amoïneu. La nova edició, encara que amb un nombre elevat de correccions, no canvia si no és en coses de detall (puntuació, mots i frases) l'obra de l'irlandès, que deu xalar com un vedell des de l'altre barri, perquè mentre es parli d'ell té assegurada la salvació estètica». Com ja he dit al començament, la present edició d'Edhasa és una reimpressió de la que va publicar Leteradura l'any 1981 i, per tant, és anterior a tota aquesta moguda. (1990)

19. Mallafrè ho ha recordat recentment, i també ha explicat que per imitar els estils històrics de Joyce va tenir com a referents Ramon Llull, les Cròniques i el Baró de Maldà, entre d'altres (Guzmán 2018). 
No va ser fins a l'edició de Proa de 1996 que Mallafrè va tenir en compte l'edició crítica de Gabler.

A l'hora de sospesar la traducció de Mallafrè avui, cal tenir en compte altres qüestions. Segons que va assenyalar ell mateix, va poder disposar de l'ajut d'acadèmics i traductors, a qui dedica paraules d'agraïment a Llengua de tribu i llengua de polis (1991: 12). En l'assaig, que — com ja hem assenyalat— aborda la traducció sobretot a partir de l'experiència de girar la novel.la de Joyce, no recull bibliografia sobre l'obra, per cert, tot i que ell ha explicat sovint fins a quin punt van ser fonamental per a ell els estudis i corpus lexicogràfics joyceans.

Pel que fa al context cultural en què la traducció de Mallafrè va veure la llum, paga la pena recordar que fins a l'any 1983 no es va aprovar la primera Llei de Normalització Lingüística i es va fundar la Corporació Catalana de Ràdio i Televisió, i que faltava encara una bona colla d'anys, a més, perquè es publiqués el controvertit assaig de Xavier Pericay i Ferran Toutain El malentès del Noucentisme (1996). Per tant, la seva versió va ser prèvia al procés d'estandardització del català escrit i oral els anys vuitanta i noranta, i a la instauració de noves polítiques de traducció de final de segle.

Carles Llorach-Freixes, al seu torn, ha publicat un nombre estimable de traduccions de l'anglès i del francès al català $\mathrm{i}$ al castellà. És, doncs, un traductor amb una trajectòria prou estimable. Tal com ha manifestat en més d'una ocasió, s'identifica amb la figura del traductor vocacional, el que «vol donar a conèixer textos que pensa que entusiasmaran els seus lectors» (2018b). Llorach va introduir-se en l'univers joyceà a partir de la traducció de Mallafrè, que va adquirir el mateix 1981, tot i que confessa que fins molts anys més tard no va ser capaç de deixar-se atrapar per la novellla (Guzmán 2018). Segons que indica, el seu original de partida va ser el «text que segueix l'edició de 1932», això és, el de l'edició de Stuart Gilbert, tot i haver consultat l'edició de Gabler de 1984 (Llorach-Freixes 2018a: 16). En tot moment ha tingut com a referència la traducció de Mallafrè, per bé que ha consultat altres traduccions, com la francesa de Morel (Guzmán 2018). Òbviament, no només ha disposat de les traduccions catalanes de Shakespeare i Dante —indica les edicions que manlleva, de Magí i Morera i Sagarra (Llorach-Freixes 2018: 18)—, sinó també d'infinitud d'estudis i fonts d'informació joyceana d'internet i, especialment, tres obres: la guia de Harry Blamires The New Bloomsday Book: A Guide Through Ulysses (2009 [1966]), les notes de Don Gifford i Robert J. Seidman compilades a Ulysses Annotated (2008 [1974]), i l'estudi de Franz Budgen James Joyce and the Making of 'Ulisses' (1972). Com explica des de la tribuna de la revista Visat, per traduir un dels capítols més complicats, el 14, va recórrer a un ampli ventall d'autors i traductors catalans, que van des de Ramon Muntaner i Ramon Llull fins a Víctor Català i Salvador Espriu (Llorach Freixes 2018b).

\section{Els paratextos}

Els paratextos de la traducció inèdita de Vidal són exclusivament autorials. El manresà va concebre, a manera de presentació, un díptic: una sumària biografia 
del novel-lista i una brevíssima nota explicativa que vol facilitar l'entrada a la complexitat de la novel-la. Quant a l'esbós biogràfic, Vidal hi consigna, bàsicament, la condició d'exiliat de Joyce, les controvèrsies generades al voltant de les seves obres i la influència que han exercit, i l'ús del monòleg interior. ${ }^{20}$ La introducció a l'obra és molt bàsica:

És el matí. En una de les torres bastides, fa temps, per a defensar la badia de Dublín, Stephen Dedalus escolta distret les improvisacions eixordadores del seu amic Mulligan, l'estudiant de medicina. Al seguit de les paraules s'enganxen els somnis i els records que s'entrecreuen com els brins de la llana d'un motiu de tapisseria. Les hores que s'escolen aporten cadascuna nous pretextos per a nous dibuixos.

El mateix Leopold Bloom, agent de publicitat, es prepara per una jornada d'aparença banal que, pels jocs de la memòria i de la imaginació, es convertirà en una veritable odissea de vint-i-quatre hores a través de Dublín.

D'un monòleg interior a l'altre, tot explicant la sola diada d'un dijous, 16 de juny de 1904, JAMES JOYCE construeix una obra atordidora en la qual es revela com un agosarat innovador.

Més enllà d'avançar qui són els dos protagonistes i l'espai i el temps de la diegesi, insisteix en la preeminència del monòleg interior i assenyala la clau interpretativa de l'obra: el relat estrafà l'odissea homèrica. Per mor de més intelligibilitat, endemés, Vidal fa alguns aclariments a peu de pàgina, però només excepcionalment. Per exemple, per indicar el joc de paraules entre «Bloom» $\mathrm{i}$ «Blood», en nota assenyala que «Blood és sang en anglès» (Joyce 1966: 215).

Contràriament, el professor Mallafrè va optar per fer arribar al lector el text nu i prescindir de qualsevol paratext autorial —una decisió que devia consensuar amb els editors. Les diferents edicions de Mallafrè s'han publicat, doncs, sense pròleg introductori ni cap aclariment en nota a peu de pàgina — per bé que el 1981 el lector català no tenia un accés fàcil a informació sobre la novellla com es té ara a Internet. ${ }^{21}$ Ell sempre ha considerat que els aclariments al voltant de

20. Reproduïm el text: «James Joyce. Nascut l'any 1862 a Rathgar, prop de Dublín (Irlanda), la manca de mitjans econòmics de la seva família fou causa d'una infantesa accidentada. James Joyce adquirí, en un colllegi de Jesuïtes, una sòlida cultura clàssica i aprengué diverses llengües estrangeres./ Durant algun temps estudià medicina, primer a Dublín i després a París; tornà a Irlanda i es féu professor./ L'any 1904 va maridar-se i, amb la seva muller, anà a Zurich i després a Trieste on romangué llarg temps./ De retorn a Dublín, l'any 1911 per a intentar la publicació d'un recull de contes, Gent de Dublín, es decidí, per fi, a editar-los per compte propi, però l'edició fou cremada per un comprador que l'adquirí totalment. Decebut de la seva terra nadiua, Joyce s'expatrià definitivament l'any 1912. Durant vint-i-cinc anys consecutius residí a Trieste, Roma i París. Morí a Zurich l'any 1941. La seva obra, molt discutida d'antuvi, es caracteritza per la utilització sistemàtica del monòleg interior. Ha exercit una influència preponderant en la novel·la contemporània./ Els seus llibres principals són: Gent de Dublín (1914), Dedalus (1914), Ulysses (1922) — qualificada com la ‘catedral de la prosa'— i Finnegans Wake (1939)».

21. Francisco García Tortosa va optar per una altra fórmula: va encapçalar la traducció amb una llarga introducció sobre l'autor, la novel-la, i uns breus resums introductoris de cada capítol a fi d'ajudar el lector a entendre millor l'Ulisses. El professor justifica: «En la traducción que ahora 
l'obra convenia fer-los des d'altres tribunes, al marge de la novella: d'aquí que hagi dut a terme una bona colla de conferències per divulgar la figura i l'obra de Joyce, a banda de publicar articles i, sobretot, el cèlebre assaig Llengua de tribu $i$ llengua de polis (1991: 111). Així doncs, per conèixer algunes de les solucions per les quals va optar, cal anar a buscar les argumentacions en aquest assaig - que segons com podria considerar-se una mena de paratext monumental a la traducció-, en què s'exposen explicacions com aquesta:

En un moment de la traducció de l'Ulisses vaig canviar la traducció de la paraula castle, que no oferia problemes aparentment i que fins en un cert moment havia traduït per castell. Però treballar al castell de Dublín volia dir treballar per a un organisme dels anglesos dominadors d'Irlanda. En comprendre això calia veure si la reexpressió fidel en català — fidel a l'esperit de Joyce— no seria una altra. Vaig traduir aquests castells per ciutadella, nom en principi neutre, però que en català podia tenir aquesta connotació de domini, des de Felip V. Se'm pot objectar, per exemple, que els lectors catalans potser no hi cauran. Però hi és, com és al text original. (Mallafrè 1991: 61)

Si a l'assaig Mallafrè indicava fins a quin punt li havien estat útils les traduccions de l'Odissea de Riba i la Divina Comèdia de Sagarra, entre d'altres (1991: 115), en la conversa radiofònica del Bloomsday 2018 recordava com va beure de la tradició literària catalana (Llull, les Cròniques medievals, el Baró de Maldà, etc.) per plasmar en la traducció la progressió històrica dels estils literaris de l'Ulisses.

En la mateixa conversa, Llorach, al seu torn, reblava els objectius que havia volgut assolir exposats a la introducció de la novellla. El primer; la seva edició aspirava a ser eminentment divulgativa, que pogués arribar sobretot als lectors joves — per a Zaro seria també, doncs, una retraducció passiva (2007: 22). I el segon; la seva proposta textual volia ser la porta d'entrada a «la traducció insuperable de Mallafrè» (Llorach 2018a: 14) —aquesta consideració abona la idea que la retraducció és un discurs doblement dialògic (Peeters 2016: 637), perquè el text de Llorach remet al de Joyce i al de Mallafrè. La supeditació a la versió de Mallafrè, Llorach l'explicava amb la metàfora següent: la retraducció pretenia equipar el lector perquè pogués «escoltar la música sense la partitura», és a dir, poder llegir l'Ulisses del reusenc sense l'ajut de les notes i els comentaris amb què ell acompanyava el text. Quant als paratextos, Llorach puntualitzava que només havia inclòs aquella informació de naturalesa més positivista fornida per la crítica especialitzada, mentre que havia prescindit de consideracions més especulatives o formulades purament per al lluïment dels crítics (Guzmán 2018).

Per diferenciar-la de la traducció de Mallafrè, l'Editorial Funambulista va posar en relleu l'agència i el paper mediador de Llorach; es tractava també, no cal

se publica se suprimen las notas explicativas, fundamentalmente porque habría que repetir lo que otros ya han dicho, y porque en una primera lectura considero aconsejable no distraer y agobiar al lector con multitud de datos; en todo caso, en lecturas subsiguientes siempre podrá consultar los libros que aquí se van recomendando» (1999 [2003: 1xxi]). 
dir-ho, d'una operació comercial. La novel-la va precedida per una introducció de Llorach que consta de quatre parts (¿Per què llegir l'Ulisses?, ¿Com llegir l'Ulis$s e s ?$, L'edició, Les notes a peu de pàgina), i incorpora comentaris explicatius a manera de sumari abans de cadascun dels 18 capítols per donar-ne les claus de lectura bàsiques, a més de nombroses notes explicatives a peu de pàgina. Finalment, l'edició inclou dues cartes de navegació: l'esquema Gilbert i l'esquema Linati. Tot plegat fa que el llibre sigui molt voluminós: 1063 pàgines. A la guarda de la coberta hi ha una fotografia del rostre de Joyce en primer pla, mentre que a la guarda de la contracoberta hi ha una fotografia del rostre de Llorach, també en primer pla.

Anna Lloveras i Roger Vilà Padró (2018), autors del blog de crítica literària L'Acció Paralllela, en la seva anàlisi estimen que

Llorach proporciona una bona introducció, uns esplèndids resums al principi de cada capítol, útils i encertats —ajuden a seguir el fil de la novellla i a veure'n els paral-lelismes amb l'Odissea d'Homer-, i un gran nombre de notes i aclariments, a voltes més útils, a voltes més prescindibles, però que delectaran els fanàtics de l'obra del dublinès. Si la informació de les notes no és sempre transcendental, almenys permet fer-se una idea de la manera com Joyce treballava, de la seva precisió i el seu domini global sobre l'obra.

A les consideracions dels bloguers convindria afegir-hi que la introducció, si bé informa sobre les fonts emprades, no s'inscriu en l'ortodòxia acadèmica: Llorach hi exposa des d'impressions personals en relació amb la novel-la fins a consells de lectura. En qualsevol cas, al nostre entendre, cal reconèixer que la majoria dels aclariments a peu de pàgina són oportuns, sobretot si es té en compte que aquesta edició ha de facilitar la comprensió de la novellla al públic més jove no només d'ara, sinó dels decennis que venen — que, tal vegada, descobriran Ulisses a partir de l'enèsima reposició del capítol «Tinc poder» (19) de la cèlebre sitcom catalana Plats bruts, representada com el súmmum de la dificultat de comprensió lectora i, justament per això, com a bagatge literari imprescindible per a qui vulgui veure's reconegut com a lector culte (Iribarren 2012a).

\section{Un tast de les traduccions}

A Llengua de tribu i llengua de polis, Mallafrè fa la reflexió següent a propòsit d'una anècdota del 1982:

Una de les coses que em va cridar l'atenció en el congrés del centenari de Joyce, a Dublín, era la quantitat de treballs en què estudiosos americans explicaven aspectes religiosos de l'obra. El desconeixement del lector americà mitjà sobre aspectes del Catolicisme era superior, tot i llegir una obra en la seva llengua, que l'aprehensió immediata del lector català que, malgrat llegir-ho en una altra, està molt més familiaritzat, en aquest aspecte, amb una cultura i una doctrina comuna amb els irlandesos, els receptors originals. (1991: 61) 
Ulisses comença amb l'inici del dia i, tal com és prescriptiu en un país catòlic com Irlanda, amb la celebració d'una missa, per bé que es tracta d'una paròdia irreverent. Per a Vidal, aquest íncipit era especialment compromès: des de bon principi, podia aixecar suspicàcies del censor. Per a Mallafrè, com acabem de veure, no semblava gaire complicat, atès que, tal com assenyala, el lector català d'inici dels vuitanta estava molt familiaritzat amb el ritual. Per contra, avui, de resultes de la secularització de la societat catalana, els lectors més joves, en general, desconeixen el ritu i la simbologia de la missa, així com d'altres referents de la cultura catòlica. És interessant, doncs, veure com Llorach aborda el passatge per fer-lo més planer per a ells. Per les raons que acabo d'exposar, el tast que he triat per caracteritzar a grans trets les tres traduccions és l'inici del primer capítol.

Joyce, edició de $1922^{22}$

Stately, plump Buck Mulligan came from the stairhead, bearing a bowl of lather on which a mirror and a razor lay crossed. A yellow dressinggown, ungirdled, was sustained gently behind him by the mild morning air. He held the bowl aloft and intoned:

- Introibo ad altare Dei.

Halted, he peered down the dark winding stairs and called up coarsely:

- Come up, Kinch. Come up, you fearful Jesuit.

Solemnly he came forward and mounted the round gunrest. He faced about and blessed gravely thrice the tower, the surrounding country and the awaking mountains. Then, catching sight of Stephen Dedalus, he bent towards him and made rapid crosses in the air, gurgling in his throat and shaking his head. Stephen Dedalus, displeased and sleepy, leaned his arms on the top of the staircase and looked coldly at the shaking gurgling face that blessed him, equine in its length, and at the light untonsured hair, grained and hued like pale oak.

Buck Mulligan peeped an instant under the mirror and then covered the bowl smartly.

- Back to barracks, he said sternly.

He added in a preacher's tone:

-For this, O dearly beloved, is the genuine Christine: body and soul and blood and ouns. Slow music, please. Shut your eyes, gents. One moment. A little trouble about those white corpuscles. Silence, all.

He peered sideways up and gave a long low whistle of call then paused awhile in rapt attention, his even white teeth glistening here and there with gold points. Chrysostomos. Two strong shrill whistles answered through the calm.

- Thanks, old chap, he cried briskly. That will do nicely. Switch off the current, will you?

\section{Vidal Jové (1966)}

BUCK MULLIGAN, imponent i flaó, aparegué dalt de tot de les escales, portador d'una bacina escumosa on reposaven, en creu, la navalla i el mirallet de mà. Dar-

22. Extret de Wikisource: <https://en.wikisource.org/wiki/Ulysses_(1922)>. Som conscients que per a ser escrupolosos hauríem d'haver fet la collació també amb l'edició de Morel i les altres edicions angleses emprades per Mallafrè i Llorach, però no ens ha estat possible per raons d'espai. 
rera seu, l'oreig suau del matí inflava dolçament la seva bata groga, sense cinyell. Aixecà la bacina i salmejà:

\section{-Introibo ad altare Dei.}

Es deturà després i, escrutant l'ombra de l'escala de caragol, engegà grollerament:

—Kinch, pugeu. Pugeu, jesuïta abominable.

I amb pas solemnial avançà vers la plataforma de tir. Giravoltant, amb gravetat, beneí per tres vegades, la torre, la contrada dels voltants, i les muntanyes que es desvetllaven. Fou aleshores que, apercebent Stephen Dedalus, s'inclinà a la seva adreça traçant ràpides creus en l'aire entre sacsejades de cap i xarroteigs. Recolzat en el graó més alt, somnolent i de mal humor, Stephen Dedalus mirava amb fredor la cara sacsejant i remugadora que el beneïa, testa cavallina, de cabells mal tallats, granelluda i del color de l'alzina clara.

Buck Mulligan havia engegat una ullada per dessota del mirall de mà i, després, havia cobert la bacina d'una revolada.

-A la caserna! -digué, categòric.

I amb to de predicaire:

- Car això, estimats meus, és la vera-vera Eucaristia: cos i ànima, malastruc. Amolleu l'orgue si us plau. Cloeu els ulls, senyores i senyors. Un instant. Això no guixa, amb aquest diantre de glòbuls blancs. Silenci tothom.

Guinyant l'ull vers el cel, modulà en to greu un llarg xiulet imperatiu; després, com pres d'un èxtasi, féu una pausa; les seves dents, iguals i blanques, s'illuminaven, d'ací d'allà, de puntetes d'or. Chrysostomos. En resposta, dues potents xiulades barrinaren la calma.

—Gràcies, vell germà, cridà amb veu alegre. Ja està bé. Talleu el corrent, si us plau.

\section{Mallafrè (2004 [1981])}

SOLEMNEMENT, el rodanxó Boc Mulligan aparegué al capdamunt de l'escala, portant un bol d'escuma amb un mirall i una navalla plans a sobre. Per darrere, l'oreig del matí aguantava suaument la bata groga, descordada. Alçà el bol salmodiant:

- Introibo ad altare Dei.

S'aturà, guaità per la fosca escala de caragol i cridà, baladrer:

-Puja, Kinx! Puja, espantable jesuïta!

Avançà amb cerimònia i pujà a la plataforma circular de tir. Mirà a l'entorn i, seriós, beneí triplement la torre, les terres al voltant i les muntanyes que es deixondien. Després, adonant-se de Stephen Dedalus, se li inclinà amb una reverència, tot fent creus en l'aire, mormolant entre dents i fent anar el cap. Stephen Dedalus, de mal humor i endormiscat, recolzà els braços a l'acabament de l'escala i mirà fredament la cara que el beneïa amb moviment barbotejant, allargassada com de cavall, i el cabell clar i intonsurat, aspre i d'un color de roure descolorit.

Boc Mulligan espià un moment a sota del mirall i de seguida tapà el bol amb picardia.

—Al quarter! —digué autoritàriament.

Afegí en to de predicador.

-Perquè això, oh estimats germans, és l'essència cristina: cos, sang, ànima i ferides. Música lenta, si us plau. Tanqueu els ulls, senyors. Un moment. Aqueixos glòbuls blancs no rutllen. Silenci, tots. 
Mirà enlaire de reüll i féu un xiulet d'atenció, lent i perllongat, després d'una pausa, embadalit, mentre les dents blanques i ben arrenglerades li lluïen ací i allà amb puntets d'or. Chrysostomos. Dos xiulets forts i aguts respongueren a través de la calma.

—Gràcies, company — cridà animadament—. Anirà bé. Vols apagar el llum?

\section{Llorach-Freixes (2018)}

SOLEMNE, EL MOLSUT BUCK MULLIGAN va sortir del forat de l'escala duent un bol d'escuma amb un mirall i una navalla d'afaitar creuats al damunt. L'airet del matí li aixecava la bata groga lleugera pel darrer, que duia descordada. [N. 1] Va alçar el bol i va salmodiar:

-Introibo ad altare Dei. [N. 2]

Es va aturar, va mirar cap a la fosca escala de cargol i va cridar amb veu grollera: -Puja, Clintx! Vinga, puja, jesuïta espantós!

Amb pas cerimoniós va avançar i es va enfilar al pedrís circular. Va girar-se i, amb posat greu, va fer tres benediccions: a la torre, al paisatge que l'envoltava $\mathrm{i}$ als turons que es desvetllaven. Aleshores, en adonar-se de l'Stephen Dedalus, li va fer una reverència i va dibuixar unes quantes creus a l'aire mentre gargaritzava $i$ remenava el cap. L'Stephen Dedalus, molest i adormit, va repenjar els braços al capdamunt de l'escala i va esguardar amb fredor aquella cara de cavall que es balancejava, feia sorolls guturals i beneïa aquells cabells esclarissats però sense tonsura, amb blens de color roure clar.

En Buck Mulligan va espiar un instant sota el mirall i va tornar a tapar el bol amb prestesa.

—En formació, ar! — va manar, contundent.

I va afegir, en to predicaire:

-Perquè això, estimats germans, és el veritable Eucaristo: el cos i la sang de Cristo. Música lenta, sisplau. Tanquin els ulls, cavallers. Un moment. Tenim un problemet amb aquests corpuscles blancs. [N. 3] Silenci, tothom.

Va mirar de reüll cap enlaire i va deixar anar un llarg i lent xiulet d'avís; tot seguit va quedar-se immòbil durant uns instants amb atenció arravatada; la seva dentadura blanca i arrenglerada va brillar, aquí i allà, amb tons daurats. Chrysostomos. [N. 4] Dos xiulets aguts hi van respondre esquerdant la calma.

—Gràcies minyó — va fer vivament. Això anirà de primera. ¿Oi que tallaràs el corrent?

NOTA 1. És la imatge de la casulla del capellà aixecada pel darrere per dos escolans. La burla a la missa és completa si suposem que en Mulligan anava despullat sota la bata.

NOTA 2. «Pujo a l'altar de Déu», en llatí. Tot el capítol està ple de referències burlesques a la celebració de la missa (que aleshores es feia en llatí) i a d'altres ritus catòlics. Irlanda, que en aquella època encara no estava constituïda en un estat independent, era profundament catòlica, mentre que Gran Bretanya era anglicana.

NOTA 3. Es refereix a les bombolles de l'escuma, que s'imagina que són hòsties.

NOTA 4. En Mulligan porta fundes d'or en algunes dents, i això du l'Stephen a pensar en sant Joan Crisòstom, «el de la boca d'or». És el primer exemple del monòleg interior que anirà impregnant el text al llarg de tot l'Ulisses. 
Dels múltiples elements a comentar d'aquests primers paràgrafs ens cenyirem exclusivament a analitzar com els traductors resolen la paròdia de la cerimònia. En Vidal veiem que busca ja d'entrada reproduir l'harmònic tan característic de l'original en repetir el mot «creu» en sentit literal i simbòlic («en creu», «creus»), mentre que en Mallafrè es perd i en Llorach hi apareix de manera més difosa («creuats», «creus»). Vidal tradueix «bowl» per «bacina» (que remet a l'univers eclesiàstic i a usos lingüístics del passat, com el mot «cinyell»), mentre que els altres dos autors opten per «bol». L'insult «fearful Jesuit»Vidal el gira per «jesuïta abominable», Mallafrè per «espantable jesuïta» i Llorach per «jesuïta espantós»: el primer és el de connotacions més negatives, atès que remet al concepte d' «impiadós». Vidal tradueix «intoned» per «salmejà», Mallafrè per «salmodiant» i Llorach per «salmodiar»: si bé semànticament no hi ha diferència entre un verb i l'altre, l'opció del manresà permet reproduir la musicalitat de l'original amb la repetició del so vocàlic «a». «Solemnly», Vidal el converteix en «I amb pas solemnial», Mallafrè en «amb cerimònia» (per evitar repetir el primer mot de la novella, «Solemnement») i Llorach «Amb pas cerimoniós» (per evitar repetir també el primer mot de la novel·la, «Solemne»); tenint en compte que tot seguit Buck Mulligan demana que comenci la música, la fórmula emprada pel manresà pot remetre a l'inici d'un ball, tot reforçant-ne la irreverència, atès que el vincula amb el verb «Giravoltant» de la frase següent, una evocació que no apareix en les altres dues propostes textuals. La reiteració del verb «blessed»Vidal i Mallafrè la mantenen de manera idèntica en traduir el primer com a «beneí» i el segon com a «beneïa»; Llorach, per contra, elimina la reiteració i opta per traduir només la primera com «va fer tres benediccions». Quant al nom «preacher», Mallafrè el tradueix per «predicador», mentre Vidal i Llorach el tradueixen per «predicaire» de clara connotació negativa; val a dir que en Vidal, a més, es vincula semànticament amb el mot «xarroteigs». La irònica cacofonia «is the genuine Christine: body and soul and blood and ouns» es perd en la proposta de Vidal que, val a dir-ho, queda forçada: «és la vera-vera Eucaristia: cos i ànima, malastruc»; Mallafrè la resol millor amb l'asíndeton «és l'essència cristina: cos, sang, ànima i ferides», que a més, amb intencions burlesques, conjuga amb la quasi homofonia entre «cristiana» $\mathrm{i}$ «cristina» (que en la segona accepció significa «rosquilla»), mentre que Llorach busca la rima amb una proposta no prou convincent: «és el veritable Eucaristo: el cos i la sang de Cristo». I finalment, l'expressió «in rapt attention» Vidal la tradueix per la irònica «en èxtasi», que evoca l'estat místic; Mallafrè empra «embadalit», mentre que Llorach tria una solució molt literal: «amb atenció arravatada». Pel que fa a la traducció de Mallafrè, cal posar en relleu que el fet de traduir el nom «Buck» per «Boc» — que en la primera accepció del diccionari de l'IEC designa el mascle de la cabra i en la segona un vas de cervesa de mig litre- reforça la burla del passatge.

Pel que fa a les notes de Llorach, i tenint en compte que han estat concebudes per als lectors més joves, totes quatre resulten oportunes - els lectors més veterans o experts en matèria joyceana, que per exemple saben perfectament que les misses es deien en llatí, poden prescindir-ne. Les notes no només aclareixen els 
referents que són objecte d'escarni al passatge, sinó que indiquen elements clau per a la comprensió de l'obra, com és el peculiar ús del monòleg interior.

Curt: la colllació d'aquest breu fragment permet sostenir que totes tres traduccions presenten encerts $\mathrm{i}$ algunes fórmules millorables. Vidal posa molt èmfasi a traduir la musicalitat joyceana i, tot i ser l'únic que havia de passar per censura, és qui carrega més les tintes en la irreverència. Mallafrè opta per naturalitzar el text —la traducció del nom Buck n'és un exemple — tot i que es pren menys llicències interpretatives que Vidal, sempre mirant de ser més fidel a l'original. I en la retraducció, Llorach torna a distanciar-se una mica més de la versió anglesa, una opció justificada pel fet que els comentaris introductoris de cada capítol i les notes ja li permeten il.luminar el sentit del text.

\section{Conclusions}

De la mateixa manera que Joaquim Mallafrè (Guzmán 2018) afirma que les tres traduccions de la Divina Comèdia al català, la d'Andreu Febrer (1429), la de Josep Maria de Sagarra (1935-1936), i la de Joan Francesc Mira (2000), són igualment vàlides, podem dir exactament el mateix quant a les tres versions de l'Ulisses.

Tenint en compte que la traducció de Vidal roman encara inèdita, i que la de Mallafrè continua sent la de referència, la proposta de Llorach és, en el seu plantejament, encertada. Brindar una retraducció divulgativa que no segueix l'ortodòxia acadèmica, que convida a (re)descobrir la traducció de Mallafrè, i que facilita la lectura d'una obra tan complexa, especialment al lector jove, resulta del tot oportú, per bé que algunes de les notes i solucions de traducció són discutibles. Llorach, com Vidal i Mallafrè, reforça el diàleg tant amb la tradició literària en llengua anglesa com amb la tradició catalana, i enriqueix el cabal lèxic i expressiu autòcton en girar un autor tan creatiu en aquest sentit com James Joyce. Cal saludar doncs, la seva retraducció: ens permet augurar que l'irlandès continuarà sent lectura canònica per al lector en català durant els decennis vinents.

\section{Referències bibliogràfiques}

AldEA, Víctor (2020). «L'Ulisses de James Joyce: l'oxímoron perfecte». Núvol (16 de juny). [en línia] <https://www.nuvol.com/llibres/lulisses-de-james-joyce-oximoronperfecte-107600>.

Blamires, Harry (2009 [1966]). The New Bloomsday Book: A Guide Through Ulysses. Londres: Routledge.

Budgen, Franz (1972). James Joyce and the Making of 'Ulisses'. Londres: Oxford University Press.

García Tortosa, Francisco (1994). «Las traducciones de Joyce al español». A: García Tortosa, Francisco; De Toro Santos, Antonio Raúl (ed.). Joyce en España I. La Coruña: Universidade da Coruña, p. 9-29.

— (1999 [2003]). «Introducción». A: JoyCE, James (1999 [2003]). Ulises. Edición de Francisco García Tortosa. Trad. de Francisco García Tortosa i María Luisa Venegas Lagǘŕns. Madrid: Cátedra, p. VII-CLXXXIX. 
Gifford, Don; Seidman, Robert J. (2008 [1974]). Ulysses Annotated. Berkeley: Los Angeles: Londres: University of California Press.

Gilbert, Stuart (1958). James Joyce's 'Ulysses'. Nova York: Vintage Books.

Guzmán, David (2018). «James Joyce i l'Ulisses». Catalunya Ràdio (16 juny). [en línia] $<$ https://www.ccma.cat/catradio/alacarta/ciutat-maragda/james-joyce-i-lulisses/ audio/1006623/\#>.

Conde-Parrilla, María-Ángeles (2012). «Ulysses, de James Joyce, en la traducción de José Salas Subirats (1945)». A: Pegenaute, Luis; Lafarga, Francisco (dir.). Biblioteca de Traducciones Hispanoamericanas. Alacant: Biblioteca Virtual Miguel de Cervantes, p. 1-14.

Corbí SÁEz, María Isabel (2002). «Les avatars de la traduction intégrale au française de l'Ulysse de James Joyce d'après la correspondance de Valery Larbaud, Adrienne Monnier, James Joyce et autres». Ull crític, 7, p. 223-241.

IrIBARREN, Teresa (2004a). «The Reception of James Joyce in Catalonia». A: LeRnout, Geert; Van Mierlo, Wim (ed.). The Reception of James Joyce in Europe. Londres: Nova York: Thoemmes Continuum, p. 445-454.

— (2004b). «James Joyce a Catalunya (1921-1936)». Els Marges, 72 (hivern), p. 21-44.

- (2011). «La primera traducció catalana de l'Ulisses (1966) de James Joyce, de Joan Francesc Vidal Jové». A: Collvinent, Sílvia; Eisner, Cornèlia; Gallén, Enric (ed.). La traducció i el món editorial català de postguerra. III Simposi sobre traducció i recepció en la literatura catalana contemporània. Lleida: Punctum; Trilcat, p. 81-94.

- (2012a). «James Joyce in Catalonia at the End of the 20th Century: High Culture and Popular Culture». Papers on Joyce, 17-18, p. 35-52.

- (2012b). «A primeira traduçâo de Ulisses na Espanha». Scientia Traductionis, 12, p. 342-363.

— (2013). «La fascinació catalana per James Joyce». Núvol (15 febrer) [en línia]. <https:// www.nuvol.com/llibres/la-fascinacio-catalana-per-james-joyce-6223>.

— (s.d.). «Joan Francesc Vidal Jové». Visat [en línia]. <http://www.visat.cat/diccionari/ cat/traductor/926/vidal-i-jove-joan-francesc.html>.

Iribarren, Teresa; Oliver, Antoni; Peiró, Esther (2017). «Recuperar traduccions inèdites per a internautes: el cas de L'illa dels pingüins, d'Anatole France, en traducció de J. F. Vidal Jové». A: Bacardí, Montserrat; Godayol, Pilar (ed.). Traducció i franquisme. Lleida: Punctum, p. 139-152.

ISERN, Joan Josep (1990). «Un clàssic renovador». Avui (Suplement de Cultura) (8 setembre).

JANÉ-Lligé, Jordi (2017). «Retraducció i models de llengua literària. La metamorfosi de Franz Kafka en català». Anuari Trilcat, 7, p. 68-110.

Joyce, James (1945). Ulises. Trad. de José Salas Subirat. Buenos Aires: Santiago Rueda.

- (1966). Ulisses. Trad. de Joan Francesc Vidal Jové. Mecanoscrit inèdit.

- (1967). Retrat de l'artista adolescent. Trad. de Maria Teresa Vernet. Barcelona: Vergara.

- (1976). Ulises. Trad. de José María Valverde. Barcelona: Lumen.

- (1981). Ulisses. Trad. de Joaquim Mallafrè. Barcelona: Leteradura [1982; Barcelona, Edhasa, 1990; ed. revisada segons edició de Gabler 1984, Barcelona: Proa, 1996; 2004].

- (1999 [2003]). Ulises. Edición de Francisco García Tortosa. Trad. Francisco García Tortosa; María Luisa Venegas Laguiéns. Madrid: Cátedra.

- (2015). Ulises. Trad. Marcelo Zabaloy. Buenos Aires: Editorial El Cuenco de Plata. 
- (2017). Ulises. Traducció, edició crítica, comentaris i notes Rolando Costa Picazo. Buenos Aires: El Cuenco de Plata.

- (2018). Ulisses. Trad. Carles Llorach-Freixes. Barcelona: El Funambulista.

L'Acció Paral-Lela [Lloveras, Anna; Vilà Padró, Roger] (2018). «Ulisses reload». [en línia] <https://accioparal.wordpress.com/2018/08/09/ulisses-reloaded/>.

Lázaro Lafuente, Alberto (2007). «El misterio del primer Ulises catalán: la odisea de Joan Francesc Vidal Jové». A: J. Henríquez, Santiago; Martín Santana, Carmen (coord.). Estudios joyceanos en Gran Canaria: Joyce «in his palms». Madrid: Huerga \& Fierro, p. 159-173.

- (2008). «Notas sobre a primeira tradución do Ulysses de Joyce ao Catalán». Viceversa: Revista Galega de Tradución, 14 , p. 217-230.

Lázaro Lafuente, Alberto; Iribarren, Teresa (2009). «Shedding Light on the Mystery of the First Catalan Ulysses: The Joycean Letters of J.F. Vidal Jové». A: New Perspectives on James Joyce. Ignatius Loyola, make haste to help me! Bilbao: Deusto University Press, p. 149-155.

Llorach-Freixes, Carles (2018a). «Unes paraules per començar». A: Joyce, James. Ulisses. Trad. Carles Llorach-Freixes. Barcelona: El Funambulista, p. 7-18.

- (2018b). «Un comentari a la meva traducció d'Ulisses». Visat, 26, p. 13-16. [en línia] <http://www.visat.cat/literatura-universal-catala/cat/ressenyes/165/60/0/29/angles/ james-joyce.html>.

MALlafrè, Joaquim (1983). «Sobre la traducció d'Ulisses al català: Notes i reflexions». Cuadernos de traducción e interpretación, 2, p. 107-115.

- (1991). Llengua de tribu i llengua de polis: Bases d'una traducció literària. Barcelona: Quaderns Crema.

Massot, Josep (2015). «La primera traducción al catalán del Ulyses de Joyce quedó inédita». La Vanguardia (10 maig). [en línia] <https://www.lavanguardia.com/cultura/ 20150510/54431158648/primera-traduccion-catalan-ulises-joyce-inedita.html>.

Peeters, Kris (2016). «Traduction, retraduction et dialogisme». Meta, 61 (3), p. 629-649.

Pericay, Xavier; Toutain, Ferran (1996). El malentès del Noucentisme. Tradició i plagi a la prosa catalana moderna. Barcelona: Proa.

Pujol, Dídac (2012). «La creativitat lèxica en la traducció catalana de l'Ulisses de Joyce: Els processos de composició». Estudis Romànics, 34, p. 335-345.

- (2013). «La creativitat lèxica en la traducció catalana de l'Ulisses de Joyce: Els processos de derivació». Estudis Romànics, 35, p. 335-344.

Saer, Juan José (2004). «El destino en español del Ulises». El País Babelia (12 juny). [en línia] <https://elpais.com/diario/2004/06/12/babelia/1086997822_850215.html>.

Venuti, Lawrence (1995). «The Scandal of Translation». A: HenRy, Freeman G. (ed.). Perceptions of Values. Amsterdam: Atlanta: Rodopi, p. 25-38.

- (2004). «Retranslations: The Creation of Value». A: Faull, Katherine M. (ed.). Translation and culture. Lewisburg: Bucknell University Press, p. 25-38.

Walsh, Keri (2016). «The Horrors and Pleasures of Translating Ulysses». Literary Hub (16 juny). [en línia] <https://lithub.com/the-horrors-and-pleasures-of-translatingulysses/>.

ZAro, Juan Jesús (2007). «Retranslations: The Creation of Value». A: ZARo VerA, Juan Jesús; Ruiz Noguera, Francisco. Retraducir. Una nueva mirada. La retraducción de textos literarios y audiovisuales. Málaga: Miguel Gómez Ediciones, p. 21-34.

VANDERSCHELDEN, Isabelle (2000). «Re-translation». A: Encyclopedia of literary translation into English. Londres: Fitzroy Dearborn, p. 1154-1155. 